\title{
Perceived Usefulness of Maritime Cross-Border Collaboration Exercises
}

\author{
Jarle Lowe Sorensen ${ }^{1 *}$, Leif Inge Magnussen ${ }^{1}$, Glenn-Egil Torgersen ${ }^{1,2}$, Atle M Christiansen ${ }^{1}$ and Eric D Carlström ${ }^{1,3}$ \\ ${ }^{1}$ University of South-Eastern Norway, Norway \\ ${ }^{2}$ Norwegian Defence University College, Norway \\ ${ }^{3}$ University of Gothenburg, Sweden
}

\begin{abstract}
The aim of this quantitative, non-experimental, survey-based study was to examine to what extent there was a statistically significant relationship between participation in a cross-border collaboration crisis exercise and experiencing perceived levels of learning and usefulness. This study reports on the data collected from a joint Norwegian-Swedish maritime Search and Rescue (SAR) collaboration exercise in April 2017. The instrument used was the Collaboration, Learning and Utility (CLU) Scale. The study showed that the inclusion of collaborative elements in the exercises contributed to perceived learning $(R=0.47)$, and that learning, in turn, contributed to perceived usefulness $(R=0.62)$. This study recommends a further focus on collaboration developing elements during exercises, including preparing for the unexpected and providing even clearer collaborative instructions.
\end{abstract}

Keywords: Collaboration; Crisis management; Exercise; CLU-scale; Learning; Usefulness; Crisis management; Search and rescue; Crossborder

\section{Introduction}

Norway and Sweden share the three national emergency preparedness principles of responsibility, equality and proximity $[1,2]$. The responsibility principles state that the organization in charge of an everyday emergency mitigation, preparedness and response task has the same area responsibility in crisis. Equality points to the organizational structure, and states that the organizational structure during crisis should mirror the everyday model. The proximity principle emphasis how incidents should be strived to be resolved at the lowest possible organizational level. Additionally, Norway introduced in 2012 the fourth principle of collaboration [3], which gave all public and NGO stakeholders an individual responsibility to facilitate, and plan for best possible cross-sector collaboration with other relevant actors. Partnerships to resolve often complex and large-scale situations

In crisis work, collaboration is considered both more advantageous and more useful than taking individual initiatives [4]. There exists an assumption that collaboration is to be developed through an emphasis on collaboration exercises [5]. The problem is that research indicates that collaboration exercises, from a participant point of view, have limited levels of learning and utility [6-14]. Sources to date are inconsistent on why exercises have a reduced perceived effect, but cited reasons point to a dominance of mechanistic exercise models [15], path-dependency [16], and an insufficient focus on the importance of variation and joint evaluations during exercises [17]. One area that has yet to be understood, and should be considered a gap in the literature, is whether these findings, which are based on national research, also apply to cross-border collaboration exercises.

Local, professionally trained emergency responders handle most daily emergencies [18]. A crisis however, is more transboundary in nature, and rarely confined by administrative and geographical boundaries [19]. When a crisis occur it tend to overwhelm available resources. To find practical working solutions, the different organizations need to combine their efforts and competencies and engage in cross-sector collaboration [20]. Collaboration became a popular working methodology in the late 80 s following a couple of decades with focus on individualism and competition [21]. Collaboration engagement is linked to the concepts of gain and reward. By combining forces and sharing risk, the stakeholders will achieve a better result than they would through the taking of individual initiatives. Thus, the participants may also achieve a higher degree of desired individual or collective rewarded or recognition [22]. While cross-sector collaboration is considered a success-factor in crisis, Berlin and Carlström [17] stated that the general problem was that accident scene stakeholders tended to avoid the best forms of collaboration. An ideal form of collaboration is a horizontal process where public and NGO stakeholders willingly work together, share information, and frequently interact across sectors and professions. Such collaboration requires a mutual understanding and agreement of that the benefits and utility values are higher than the costs of taking individual initiatives. Cross-sector collaboration does not just occur by having different organizations and stakeholders coming together at the same accident site. It has to be learned and developed through an emphasis on collaboration exercises [1,23].

The concept of learning is in this study based on Stein 's [24] first and second order learning theories, where the goal is to acquire second-order learning where the exercise participants bring with them, and apply exercise knowledge into real-life crisis work. Borell and Eriksson [25] therefore argued that collaboration exercises should be considered tools rather than permanent solutions and perfect designed scripts. An exercises goal should not be to practice predefined tasks or sector specific drilling, but rather focus on cross-sector collaboration learning and enhancement of cross-sector performance. Sommer and Njå [26] argued several ways to enhance learning, including drawing on personal and joint experiences and participation in joint evaluation forums. Further, for participants to perceive collaboration learning and utility, the exercises need to have a clearly stated collaboration focus, be limited in scope, and provide clear instructions [27]. To encourage and facilitate collaboration across sectors, the participants have to develop a clearer understanding of other participating organizations'

*Corresponding author: Jarle Løwe Sørensen, School of Business, University of South-Eastern Norway, Norway, Tel: +47 99238 930; E-mail: Jarle.sorensen@usn.no

Received May 09, 2018; Accepted May 21, 2018; Published May 28, 2018

Citation: Sorensen JL, Magnussen LI, Torgersen GE, Christiansen AM, Carlström ED (2018) Perceived Usefulness of Maritime Cross-Border Collaboration Exercises. Arts Social Sci J 9: 361. doi: 10.4172/2151-6200.1000361

Copyright: (c) 2018 Sorensen JL, et al. This is an open-access article distributed under the terms of the Creative Commons Attribution License, which permits unrestricted use, distribution, and reproduction in any medium, provided the original author and source are credited. 
priorities, ways of communicating, and use of sector specific terms and abbreviations [17].

For cross-sector collaboration to be successful, both public and NGO stakeholders need to have a basic level of cross-sector understanding and trust [28]. Pramanik, et al. [29] discovered a tendency of strong ingroup bias among exercise participants, and argued that participants found it easier to collaborate with, and trust, participants they could identify with based on, for example, similar educational background, professional experiences or type of uniform. To build trust across sectors, exercise designers have to focus on joint problem solving and variation during exercises, hence allowing for improvisation and the trying of new strategies contributes to enhance learning [30]. Having the ability to improvise and come up with alternative solutions also helps crisis stakeholders respond to and manage the unforeseen, which in crisis management, refers to coping with and addressing incidents that occur relatively unexpectedly, with a low degree of probability and predictability $[31,32]$

\section{Materials and Methods}

This was a quantitative, non-experimental, survey-based study. Participants, who had indicated their willingness to take part, received an online Quest Back-based survey following the exercise. The survey was provided in both Norwegian and Swedish. The Collaboration, Learning and Utility Scale (CLU-Scale) was the instrument of choice for measuring the effects of collaboration exercises [8]. Based on a 5-point Likert Scale ranging from 1 (strongly disagree) to 5 (strongly agree), the instrument captured the participants' perceived levels of collaboration, learning and utility items. The Cronbach's alpha was calculated to test the homogeneity of the items. The results showed an alpha of .88. Statistical significance was $\mathrm{p}<0.05$ and all tests were two-tailed [33]. The analysis stems primarily from descriptive data and regressions (bivariate and multiple). Means and standard deviations were used for descriptive purposes. To ensure that the study was conducted in accordance with ethical research standards, permission had been sought from the Norwegian Center for Research Data prior to data collection.

\section{Study context}

This study reports on the data collected from a joint NorwegianSwedish maritime Search and Rescue (SAR) collaboration exercise in April 2017. The exercise studied was a joint Norwegian-Swedish Maritime Search and Rescue (SAR) collaboration exercise. The exercise scenario occurred on the Swedish west coast, near the Norwegian border in April 2017. The Swedish Maritime Administration served as exercise coordinators. The plot involved 10 kayakers in distress. The exercise area covered 50,000 square metres covering shoals and islets. The exercise ran for 7 hours, including pre-brief and debrief. The weather was sunny with winds up to 8 or 9 metres per second, and with air temperatures of around 10 degrees Celsius.

\section{Population and sample}

Ninety people participated in the exercise. The involved organizations belonged to the Norwegian and Swedish Societies for Sea Rescue, the Swedish police, Swedish fire and rescue services, and Norwegian SAR helicopters. Ten participants were members of a local Swedish sea-kayak club, who served as markers during the exercise. The exercise included two rescue helicopters and six SAR vessels. The Swedish Maritime Administration served as exercise organizer. Sixty-two persons willingly shared their email addresses and agreed to respond to the post-exercise online survey.

\section{Analysis}

The analysis process started by analysing the distribution of demographics, before analysing the collaboration, learning and usefulness characteristics. To describe the variations in data distribution, mean values were calculated, and standard deviations were identified [34]. Two bivariate regression analyses tested the effects of collaboration, learning and usefulness. The first analyses tested the relationship between collaboration and learning, and the second tested the relationship between learning and usefulness. The demographical data were not included in the regression analysis as they were collected for descriptive purposes only. An assumption was made that collaboration leads to learning, and that learning again leads to usefulness. In the first test, collaboration served as the independent variable relative to learning (the dependent variable). In the second, learning served as the independent variable relative to usefulness. To measure the linear dependence between the variables, Pearson correlation coefficients (Pearson's r) were calculated. The coefficients of determination $\left(\mathrm{r}^{2}\right)$ were also calculated to define what proportions of the variance in the dependent variables could be predicted from the independent variables [35]. The F-value was determined to detect any differences in variance [34] while the significance level (p-value) was computed to determine the probability of rejecting the null hypothesis. Variables from the bivariate regressions that were found to be significant were then tested in a multiple regression analysis). Collaboration and learning were used as integrated independent variables relative to usefulness. Standard Beta and p-values were calculated.

\section{Results}

\section{Demographics}

Of the 62 persons invited to participate in the study, 30 responded to the online survey (response rate $=48 \%$ ). Twenty-five were males and five were females. The population's ages varied between 25 and 72. Age was divided into 4 groups; 25-34, 35-44, 45-54 and 55+. The respondents were evenly distributed throughout the groups with eight persons belonging to each of the first three groups, and 5 to the $55+$ group. One person did not respond. As many as $43.3 \%$ had participated in 11 or more collaboration exercises during the last five years $(M=3.55$, $\mathrm{SD}=1.55$ ). Members from all the involved organizations contributed to the study.

\section{Collaboration characteristics}

The respondents either mildly (23.3\%) or strongly (76.7\%) agree that the exercise focused on collaboration $(\mathrm{M}=4.76, \mathrm{SD}=0.43)$. While $20 \%$ disagreed that the exercise had provided sufficient discussions (i.e. seminars) directly following the exercise, $26.6 \%$ agreed. However, a majority $(53.3 \%)$ remained neutral $(\mathrm{M}=3.00, \mathrm{SD}=1.05)$. Summed, $50 \%$ agreed that there was room for improvising while $30 \%$ remained neutral $(\mathrm{M}=3.33, \mathrm{SD}=1.06)$. A clear majority $(90.0 \%)$ agreed that collaboration was initiated immediately the exercise started without unnecessary waiting time $(\mathrm{M}=4.46, \mathrm{SD}=0.90)$. In total, $73.3 \%$ agreed that they had performed activities during the exercise that were already well known to them, while $23.3 \%$ remained neutral $(M=4.16, S D=1.01)$. When it came to whether the exercise scenario targeted the right personnel, less than half $(46.7 \%)$ agreed, and 30\% remained neutral $(\mathrm{M}=3.46, \mathrm{SD}=1.28)$. Exactly half $(50.0 \%)$ agreed that clear instructions for collaborative practice were presented, while $36.7 \%$ percent remained neutral, and $13.3 \%$ mildly disagreed $(\mathrm{M}=3.60, \mathrm{SD}=1.00)$. Of the respondents, just over half $(53.3 \%)$ agreed that their points of view had been considered. The rest $(46.7 \%)$ remained neutral $(\mathrm{M}=3.93, \mathrm{SD}=0.94)$. The total 
joint mean for the collaboration dimension was 3.83 , with a standard deviation of 0.40 .

\section{Learning characteristics}

Most of the respondents (73.4\%) agreed that they gained new knowledge through their participation in the exercise, while $16.7 \%$ disagreed $(\mathrm{M}=3.86, \mathrm{SD}=1.22)$. Most (76.6\%) agreed that they had learned something about the collaborating organizations' organizational management aspects $(\mathrm{M}=4.13, \mathrm{SD}=0.93)$, and a clear majority $(80.0 \%)$ agreed that they had learned something about the other organizations' communication patterns $(\mathrm{M}=4.23, \mathrm{SD}=0.93)$. While just over half (53.3\%) agreed that they had learned about how the other organizations prioritize their activities, 36.7\% remained neutral $(\mathrm{M}=3.50, \mathrm{SD}=0.90)$. Of the respondents, $33.3 \%$ agreed that they had learned new concepts and abbreviations during the exercise, $40 \%$ somewhat or strongly disagreed, and $26.7 \%$ remained neutral $(\mathrm{M}=2.83$, $\mathrm{SD}=1.36$ ). The total joint mean for the learning dimension was 3.71 , with a standard deviation of 0.77 .

\section{Usefulness characteristics}

Sixty percent of the sampled population perceived, based on what they had learned, that the exercise was useful for real-life activities during actual emergency work. Only 10.0\% disagreed, however, $30.0 \%$ remained neutral $(\mathrm{M}=3.80, \mathrm{SD}=1.18)$. While $33.3 \%$ agreed that the exercise was useful to command officers, almost half (46.7\%) remained neutral $(\mathrm{M}=3.33, \mathrm{SD}=1.02)$. When asked, based on what they had learned, whether the exercise was useful to ordinary operative staff (command officers not included), only $26.7 \%$ agreed, while over half (60.0\%) remained neutral $(\mathrm{M}=3.23, \mathrm{SD}=1.04 \%)$. Finally, half $(50.0 \%)$ perceived, based on what they had learned, that the experiences from the exercise would affect their daily work, $13.4 \%$ disagreed, and $36.7 \%$ remained neutral $(\mathrm{M}=3.43, \mathrm{SD}=1.04)$. The total joint mean for the usefulness dimension was 3.45 , with a standard deviation of 0.67 .

\section{Bivariate regression analysis}

Several bivariate regression analyses tested the effects of collaboration, learning and usefulness. In the first analysis, the collaboration items served as independent variables to the indexed learning variable. The most pronounced significance was found between learning and the item "My points of view were regarded" $(\mathrm{r}=0.39)$, which explained a significant proportion of the mean learning score $\left(\mathrm{r}^{2}=0.01, F=5.00, p \leq 0.03\right)$, followed by the item "Sufficient forms of discussion were provided" $\left(\mathrm{R}=0.35, \mathrm{r}^{2}=0.09, \mathrm{~F}=3.88, \mathrm{p} \leq 0.05\right)$. These items were closely followed by the items "There were opportunities to improvise" with an R-value of $0.32\left(\mathrm{r}^{2}=0.07, \mathrm{~F}=3.26, \mathrm{p} \leq 0.08\right)$, and "The exercises were focused on collaboration" $\left(r=0.29, r^{2}=0.05, F=2.57 p \leq\right.$ 0.12). The item "Personnel in need of exercises participated" displayed an R-value of $0.20\left(\mathrm{r}^{2}=0.01, \mathrm{~F}=1.19 \mathrm{p} \leq 0.28\right)$. Somewhat weaker correlations were found in the remaining items "I performed wellknown activities" ( $\left.\mathrm{r} 0.14, \mathrm{r}^{2}=-0.01, \mathrm{~F}=0.57 \mathrm{p} \leq 0.45\right)$, "Collaboration was initiated immediately" ( $\left.\mathrm{r}=0.06, \mathrm{r}^{2}-0.03, \mathrm{~F}=0.13 \mathrm{p} \leq 0.71\right)$, and "Clear instructions about collaboration were presented" ( $\mathrm{r}=0.05$, $\mathrm{r}^{2}=0.02, \mathrm{~F}=1.69 \mathrm{p} \leq 0.20$ ). In the second bivariate regression analysis, the learning characteristics served as the independent variables to usefulness (dependent). The most pronounced significance was found between usefulness and the item "I learned new things during the exercise" $\left(\mathrm{r}=0.58, \mathrm{r}^{2}=0.31, \mathrm{~F}=14.15 \mathrm{p} \leq 0.00\right)$. It was followed by the items "I learned others' concepts and abbreviations" $\left(r=0.50, r^{2}=0.22\right.$, $\mathrm{F}=9.25, \mathrm{p} \leq 0.00$ ), and "I learned about others' prioritizing of activities" $\left(\mathrm{r}=0.32, \mathrm{r}^{2}=0.07, \mathrm{~F}=3.38, \mathrm{p} \leq 0.07\right)$. The item "I learned about others' organizational aspects" showed an R-value of $0.31\left(\mathrm{r}^{2}=0.06, \mathrm{~F}=3.03, \mathrm{p} \leq\right.$ 0.09). Last, the item "I learned about others' communication patterns" indicated an $\mathrm{R}$-value of $0.18\left(\mathrm{r}^{2}=-0.00, \mathrm{~F}=0.98, \mathrm{p} \leq 0.33\right)$ (Tables 1 and 2).

\section{Multiple regression analysis}

Following the bivariate regression analysis, variables that were found to be significant were tested in two multiple regression analyses. The first analysis tested the collaboration dimension of learning, and the second tested the learning dimension of usefulness. The standardized coefficients (i.e., beta coefficients) and the significance levels (p-values) were identified.

In the first multiple regression analysis, the collaborative variables "Sufficient forms of discussion were provided" ( $\mathrm{p}=0.05)$ and "My points of view were regarded" ( $p=0.03)$ had been identified as significant. Jointly, the collaborative characteristics predicted $16 \%\left(\mathrm{r}^{2}=0.16\right)$ of the learning variance, which left the remaining $84 \%$ unaccounted for.

\section{Dependent variable: Learning \\ Independent Variables: Collaborative characteristics of exercises}

\begin{tabular}{|c|c|c|c|c|}
\hline & $\mathbf{R}$ & $\mathbf{R}^{2}$ & $\boldsymbol{F}$ & Signif. (p) \\
\hline The exercises were focused on collaboration & 0.29 & 0.05 & 2.57 & 0.12 \\
\hline Sufficient forms of discussion were provided & 0.35 & 0.09 & 3.88 & 0.05 \\
\hline There were opportunities to improvise & 0.32 & 0.07 & 3.26 & 0.08 \\
\hline Collaboration was initiated immediately & 0.06 & -0.03 & 0.13 & 0.71 \\
\hline I performed well-known activities & 0.14 & -0.01 & 0.57 & 0.45 \\
\hline Personnel in need of exercises participated & 0.2 & 0.01 & 1.19 & 0.28 \\
\hline Clear collaboration instructions presented & 0.05 & 0.02 & 1.69 & 0.2 \\
\hline My points of view were regarded & 0.39 & 0.01 & 5 & 0.03 \\
\hline
\end{tabular}

Table 1: Bivariate regression of the collaboration dimensions of learning

\section{Dependent variable: Usefulness}

Independent Variables: Learning characteristics

\begin{tabular}{|c|c|c|c|c|}
\hline & $\mathbf{R}$ & $\mathbf{R}^{2}$ & $\boldsymbol{F}$ & Signif. (p) \\
\hline I learned new things during the exercise & 0.58 & 0.31 & 14.15 & 0 \\
\hline I learned about others' organizational aspects & 0.31 & 0.06 & 3.03 & 0.09 \\
\hline I learned about others' communication patterns & 0.18 & 0 & 0.98 & 0.33 \\
\hline I learned about others' prioritizing of activities & 0.32 & 0.07 & 3.38 & 0.07 \\
\hline I learned others' concepts and abbreviations & 0.5 & 0.22 & 9.25 & 0 \\
\hline
\end{tabular}

Table 2: Bivariate regression of the learning dimension of usefulness. 
None of the variables from the multiple regression analysis ended up significant. The analysis indicated a $47 \%(\mathrm{r}=0.47)$ covariation between collaboration and learning, which is to be considered medium [36]. In the second analysis, the learning dimension of usefulness was tested. The variables found to be significant from the bivariate regressions were "I learned new things during the exercise" $(\mathrm{p}=0.00)$ and "I learned others' concepts and abbreviations" $(\mathrm{p}=0.00)$. It was noted that the learning characteristics predicted $38 \%\left(\mathrm{r}^{2}=0.38\right)$ of the learning variance, which left the remaining $62 \%$ unaccounted for. The variable "I learned new things during the exercise" was found significant $(\mathrm{p}=0.02)$. The analysis indicated a $62 \%(\mathrm{r}=0.62)$ covariation between learning and usefulness, which is to be considered strong (Tables 3 and 4) [36]

\section{Discussion}

The study results indicated that a focus on collaboration leads to perceived increased learning and usefulness in crisis work. However, the overall descriptive learning results were still to be considered somewhat modest. While $73.4 \%$ agreed they had learned new things through their participation in the exercise, only just above half $(60 \%)$ of the sampled population perceived, based on what they had learned, that the exercise was useful to real-life activities. Only half (50\%) perceived, based on what they had learned, that the experiences from the exercise would affect their daily work. While only a small percentage (13.4\%) disagreed that they would bring elements from the exercise with them into real crisis work, over a third (36.7\%) remained neutral. These findings suggested that the collaboration exercise, perceivably, did not fully prepare crisis stakeholders for cross-sector collaboration in real crises. Results indicated a room for improvement when it came to focusing on collaboration development before, during and after the exercise.

A prompting factor can be found in the population sample's response to the item "I performed well-known activities," with which over half $(73.3 \%)$ of the respondents agreed. Such results indicated that the exercise organizers could have paid more attention to variation, and signalled that the exercise participants likely engaged in daily drill procedures rather than focusing on collaboration development. Compared to collaboration exercises, which focus on collaboration between stakeholders in terms of preparedness integration, and behavioural response [5] drills are designed to repeat discipline-specific key routines, i.e. standard operating routines such as equipment handling or procedure undertaking [8]. That the participants prior to and during the exercise did not have detailed knowledge of the

\begin{tabular}{|c|c|c|c|c|}
\hline \multicolumn{5}{|c|}{$\begin{array}{l}\text { Dependent Variable: Learning } \\
\text { Independent Variables: Collaboration characteristics }\end{array}$} \\
\hline & $\begin{array}{l}\text { Biv. regr. } \\
\text { Stand. Beta }\end{array}$ & $\begin{array}{l}\text { Mult. regr. } \\
\text { Stand. Beta }\end{array}$ & Diff. & Signif. (p) \\
\hline $\begin{array}{l}\text { Sufficient forms of } \\
\text { discussion were provided }\end{array}$ & 0.35 & 0.27 & 0.08 & 0.13 \\
\hline $\begin{array}{l}\text { My points of view were } \\
\text { regarded }\end{array}$ & 0.39 & 0.32 & 0.07 & 0.07 \\
\hline
\end{tabular}

Table 3: Multiple Regression of the collaboration dimensions of learning.

\begin{tabular}{|c|c|c|c|c|}
\hline \multicolumn{5}{|c|}{$\begin{array}{l}\text { Dependent Variable: Learning } \\
\text { Independent Variables: Collaboration characteristics }\end{array}$} \\
\hline & $\begin{array}{l}\text { Biv. regr. } \\
\text { Stand. Beta }\end{array}$ & $\begin{array}{l}\text { Mult. regr. } \\
\text { Stand. Beta }\end{array}$ & Diff. & Signif. (p) \\
\hline $\begin{array}{l}\text { I learned new things } \\
\text { during the exercise }\end{array}$ & 0.58 & 0.44 & 0.14 & 0.02 \\
\hline $\begin{array}{l}\text { I learned others' concepts } \\
\text { and abbreviations }\end{array}$ & 0.5 & 0.26 & 0,24 & 0.16 \\
\hline
\end{tabular}

Table 4: Multiple regression of the learning dimensions of usefulness. unfolding scenario, indicates that the exercise had elements of the unexpected [32]. A Crisis Management success factor is to combine and facilitate the needs for structural flexibility and stability in times of crisis [30]. In this exercise, half (50\%) agreed that there was room for improvising, while $30 \%$ remained neutral. These findings suggested that the unfolding scenario added to sector specific standardized behaviour, rather than testing new strategies and inventive behaviour [9]. Still, results indicated that some collaborative elements were present during the exercise, as slightly above half $(53.3 \%)$ agreed that their points of view had been considered [10].

The total joint mean for the collaboration dimension $(\mathrm{M}=3.83)$ based on a five-point Likert scale suggested a relatively open collaborative climate during the exercise. For example, the respondents either mildly $(23.3 \%)$ or strongly $(76.7 \%)$ agreed that the exercise focused on collaboration. However, over half (53.3\%) remained neutral to the question of whether the exercise had provided sufficient discussions (i.e. seminars) directly following the exercise, which may indicate that the design of the hot wash-up did not provide an optimal arena for increased learning in terms of sharing experiences and engaging in joint problem-solving processes [26]. When it came to learning, most of the respondents (73.4\%) agreed that they learned new things through their participation in the exercise. However, the total joint mean for the learning dimension was 3.71, which indicated that there was room for learning development. While most agreed that they learned something about the collaborating organizations' organizational management aspects $(76.6 \%)$ and communication patterns $(80.0 \%)$, only half $(53.3 \%)$ agreed that they had learned about how the other organizations' prioritize their activities. The result may mirror a substantial learning potential in interpreted communication in two slightly different languages. Furthermore, the organizational management differed between Sweden and Norway. In Norway, the police department have more influence in leading accident sites than in Sweden. Only 33.3\% agreed that they had learned new concepts and abbreviations during the exercise, $40 \%$ disagreed. The result indicates a need to put more efforts into seminars identifying similarities and differences in communication and the use of acronyms by the collaborating parties. Upon examining the degree of perceived usefulness, the results indicated that only $26.7 \%$ agreed that the exercise was useful to ordinary operative staff, while $33.3 \%$ agreed that the exercise was useful to command officers. These findings indicated that the overall level of perceived learning during the exercise had been somewhat limited for both operatives and managers. This assumption was also confirmed by the response to the question on whether the exercise would affect their daily work, where only half (50.0\%) agreed and $36.7 \%$ remained neutral.

An important result of the study was that an increased focus on collaboration and learning leads to increased perceived usefulness in real crisis work. The study showed the importance of cross-border exercises, as, while the approach to crisis work is mostly similar, there are some organizational differences between Norwegian and Swedish SAR services, e.g. at the management level, which may lead to misunderstandings in real crisis work. Therefore, identifying differences in routines and procedures leads to increased understanding, which again leads to increased learning and usefulness. The studied exercise was well organized, provided a relevant scenario, and facilitated a joint organized evaluation immediately following the exercise. However, the results indicate that the level of perceived learning was somewhat limited, and that there was room for increased learning. Crisis collaboration exercises should not be viewed as permanent solutions, but rather as learning instruments, where participants learn 
how to work together, improvise and deal with the [25]. It is therefore important that all cross-sector collaboration exercises emphasize collaboration learning rather than focusing on fulfilling sector specific scripts. Getting crisis stakeholders to engage in desired collaboration behaviour in times of crisis and during exercises is challenging. A further focus on collaborative elements such as preparing for the unexpected and providing even clearer collaborative instructions may increase the overall perceived usefulness

\section{Limitations}

This study was limited in scope, as the data were gathered from one exercise only. However, due to the few maritime cross-border SAR collaboration exercises conducted between Norway and Sweden in 2017, data collected from this exercise gave a good indication of the participants' current and perceived levels of collaboration, learning and usefulness. An assumption was that the chosen sample population, based on their professional affiliation and experience, had sufficient knowledge of SAR collaboration to participate in the study. Data was collected one week after the exercise. The study did not address the effect of this collaboration on real-life events, nor the effect of previous exercises and rescue practice. Even if there are some obvious differences in routines, organization and communication between the two countries, they have several similarities in language, culture and routines. In an expanded study, a multinational maritime collaboration should be of great value.

\section{References}

1. Norwegian Ministry of Justice and Public Security (2018).

2. Swedish Civil Contingencies Agency (2018) Civil Emergency Planning/Crisis Management in Sweden.

3. Norwegian Ministry of Justice and Public Security (2012) Melding til Stortinget 29 Samfunnssikkerhet [White paper 29 (2011-2012) civil preparedness].

4. Berlin J, Carlström E (2008) The 90-Second collaboration: A critical study of collaboration exercises at extensive accident sites. Journal of Contingencies, Crisis Management 16: 177-185.

5. Rutty GN, Rutty JE (2012) Did the participants of the mass fatality exercise Operation Torch learn anything? Forensic Science Medicine and Pathology 8: 88-93.

6. Berlin J, Carlström E (2009) Samverken på olyksplassen [Collaboration at the accident scene] Gothenburg: University West.

7. Berlin J, Carlström E (2013) The dominance of mechanistic behaviour: A critical study of emergency exercises. International Journal of Emergency Management 9: 327-350.

8. Berlin J, Carlström E (2015) Collaboration exercises: What do they contribute? A study of learning and usefulness. Journal of Contingencies and Crisis Management 23: 11-23.

9. $\mathrm{Kim} \mathrm{H}(2013)$ Improving simulation exercises in Korea for disaster preparedness. Disaster Prevention and Management 22: 38-47.

10. Kim H (2014) Learning from UK disaster exercises: Policy implications for effective emergency preparedness. Disasters 38: 846-857.

11. Kristiansen E, Sorensen JL, Carlström E, Magnussen LI (2017) Time to rethink Norwegian maritime collaboration exercises. International Journal of Emergency Services 6: 14-28.

12. Magnussen LI, Carlstrøm E, Sørensen JL, Torgersen GE, Hagenes EF, et al. (2018) Learning and usefulness stemming from collaboration in a maritime crisis management exercise in Northern Norway. Disaster Prevention and Management: An International Journal 27: 129-140.
13. Perry R (2004) Disaster exercises' outcomes for professional emergency personnel and citizen volunteers. Journal of Contingencies and Crisis Management 12: 64-75.

14. Sorensen JL (2017) Norwegian Maritime Crisis Collaboration Exercises: Are They Useful? (Doctoral dissertation Northcentral University).

15. Burns T, Stalker GM (1961) The Management of Innovation London: Tavistock.

16. Selznick $P$ (1957) Leadership in administration: A sociological interpretation Berkeley California.

17. Berlin J, Carlström E (2011) Why is collaboration minimised at the accident scene? A critical study of a hidden phenomenon Disaster Prevention and Management 20: 159-171.

18. Andersson A, Carlstrom E, Ahgren B, Berlin J (2014) Managing boundaries at the accident scene - a qualitative study of collaboration exercises. International Journal of Emergency Services 3: 77-94.

19. Ansell C, Boin A, Keller A (2010) Managing transboundary crises: Identifying the building blocks of an effective response system. Journal of Contingencies and Crisis Management 18: 195-207.

20. Boin A, Bynander $F$ (2015) Explaining success and failure in crisis coordination Geografiska Annaler Series A: Physical Geography 97: 123-135.

21. Axelsson $R$ (2000) The organizational pendulum: Healthcare management in Sweden 1865-1998 Scandinavian. Journal of Public Health 28: 47-53.

22. Mill JS (1859/2000) On Liberty Dover Publications New York.

23. Swedish Civil Contingencies (2011) Utvärdering av SAMÖ/KKÖ 2011 Swedish Civil Contingencies Agency (MSB) Stockholm.

24. Stein J (1997) How Institutions Learn: A Socio-Cognitive Perspective. Journa of Economic Issues (Association for Evolutionary Economics) 31: 729-740.

25. Borell J, Eriksson K (2013) Learning effectiveness of discussion-based crisis management exercises. International Journal of Disaster Risk Reduction 5: 28-37.

26. Sommer M, Njå O (2012) Dominant learning processes in emergency response organizations: A case study of a joint rescue coordination centre. Journal of Contingencies and Crisis Management 20: 219-230.

27. Andersson A, Carlström E, Berlin J (2013) Organizing a simulated reality: On exercises with public safety organizations [Organisering Av En fingerad Verklighet: Om ovningar mellan blåljusorganisationer] Nordic Organization Studies 15: 34-64.

28. Curnin S, Owen C, Paton D, Brooks B (2015) A theoretical framework for negotiating the path of emergency management multi-agency coordination. Applied Ergonomics 47: 300-307.

29. Pramanik R, Ekman O, Hassel H, Tehler H (2015) Organizational adaptation in multi-stakeholder crisis response: An experimental study. Journal of Contingencies andCrisis Management 2: 234-245.

30. Christensen T, Danielsen A, Lægreid P, Rykkja L (2015) Comparing coordination structures for crisis management in six countries. Public Administration.

31. Torgersen GE, Steiro TJ, Saeverot H (2013) Strategic education management: Outlines for a didactic planning model for exercises and training of the unexpected in high risk organizations. In Proceedings of the 22nd Society for Risk Analysis Europe (SRA E) Conference.

32. Torgersen GE (2015) Pedagogikk for det uforutsette [Pedagogy for the Unforeseen] Bergen/Oslo: Fagbokforlaget.

33. Altman DG (1991) Practical statistics for medical research New York: Chapman and Hall.

34. Bennett J, Briggs W, Triola M (2014) Statistical reasoning for everyday life (4thedn), Harlow United Kingdom: Pearson.

35. Trochim W, Donnelly J (2008) The research methods knowledge base (3rdedn) Boston MA: Cengage Learning

36. Cohen J (1988) Statistical power analysis for the behavioral sciences (2ndedn) St Paul MN: West. 